\title{
Cartilaginous Choristoma in Tonsil : A Rare entity
}

\author{
Sujan Sharma, ${ }^{1{ }^{*}}$ Ramesh Makaju, ${ }^{1}$ Bikash Shrestha ${ }^{2}$
}

Choristoma is a tumor like mass consisting of tissues foreign to the site at which they are located. We report a 39-year-old female who presented to our out-patient department with history of pain and burning sensation in the throat. On examination of the tonsils, bilateral keratosis was present. Histological examination demonstrated the unexpected presence of mature hyaline cartilage surrounded by lymphoid follicles.

Keywords: Tonsil; Cartilaginous Choristoma

(C) 2015 Nepalese Association for Clinical Chemistry

\section{Introduction}

Choristoma is an island of normal tissue in an abnormal location Cartilaginous choristoma was first described by Berry in 1890 [1]. The age of diagnosis varies greatly from 10 to 80 years. Choristoma in the head and neck region was reported in the pharynx, hypopharynx, oral mucosa and middle ear [2]. Here we report a case of 39-year-old female who was clinically diagnosed as tonsillar keratosis. On histopathological examination mature hyaline cartilage were found surrounded by lymphoid follicles.

\section{Case Report:}

A 39-year-old female who presented to our Otolaryngology out patient department with history of pain and burning sensation in the throat right side was more than the left .The remainder of the head and neck was free of mass lesions and other significant findings. On examination of the tonsils, bilateral keratosis was present. Patient was admitted in the Otolaryngology ward and was managed surgically as there was no improvement despite all conservative measures. Operative findings was grade I enlarged bilateral tonsils with keratosis in bilateral tonsillar crypts. Tonsillectomy was performed and the specimen was sent for histopathological examinations.

Histopathological examination of the specimen showed follicular hyperplasia in association with islands of mature hyaline cartilage as cartilaginous choristoma in tonsil.

\section{Discussion:}

The neck is developmentally complex, with frequent embryologic anomalies. Heterotopic tissue as hamartoma or choristoma is another interesting findings [3]. Cartilaginous choristoma was first described by Berry in $1890[1,4]$. The age group ranges widely from 10 to 80 years. The other sites at which they occur are pharynx, hypopharynx, oral mucosa and middle ear $[5,6]$.

Various mechanisms have been suggested for pathogenesis of hetrotopia, that are multi- lineage potential of mesenchymal progenitors cells which were able to differentiate into various mesenchymal lineages, as proposed by Haemel et al. [7]. Chondroid choristomas of the tongue are more common in females, although in palantile tonsil they do not have any sex predilection [6]. Choristoma of the tonsil appears to be a developmental anomaly associated with the second pharyngeal arch and could be one of the cause of recurrent tonsillitis. Few other opine that extraskeletal proliferation of cartilage in oral cavity and maxillofacial soft tissue probably reflects the multipotential nature of primitive mesenchymal cells, which may be stimulated to grow by trauma, irritation, or inflammation [8]. Presence of choristoma in the tonsil is extremely rare. Erkilic et al., in their study of routine tonsillectomy specimens found a $3 \%$ incidence of cartilage in the tonsillar tissue.

In view of recurrence seen in certain extraoral cases, excision should involve removal of perichondrium, because it may have the potential to develop new cartilage $[9,10]$.

To conclude, choristomas are rare entity and of academic interest. Although they are rare, a high index of suspicion for choristomas is needed, when a patient with recurrent tonsillitis is being evaluated. 


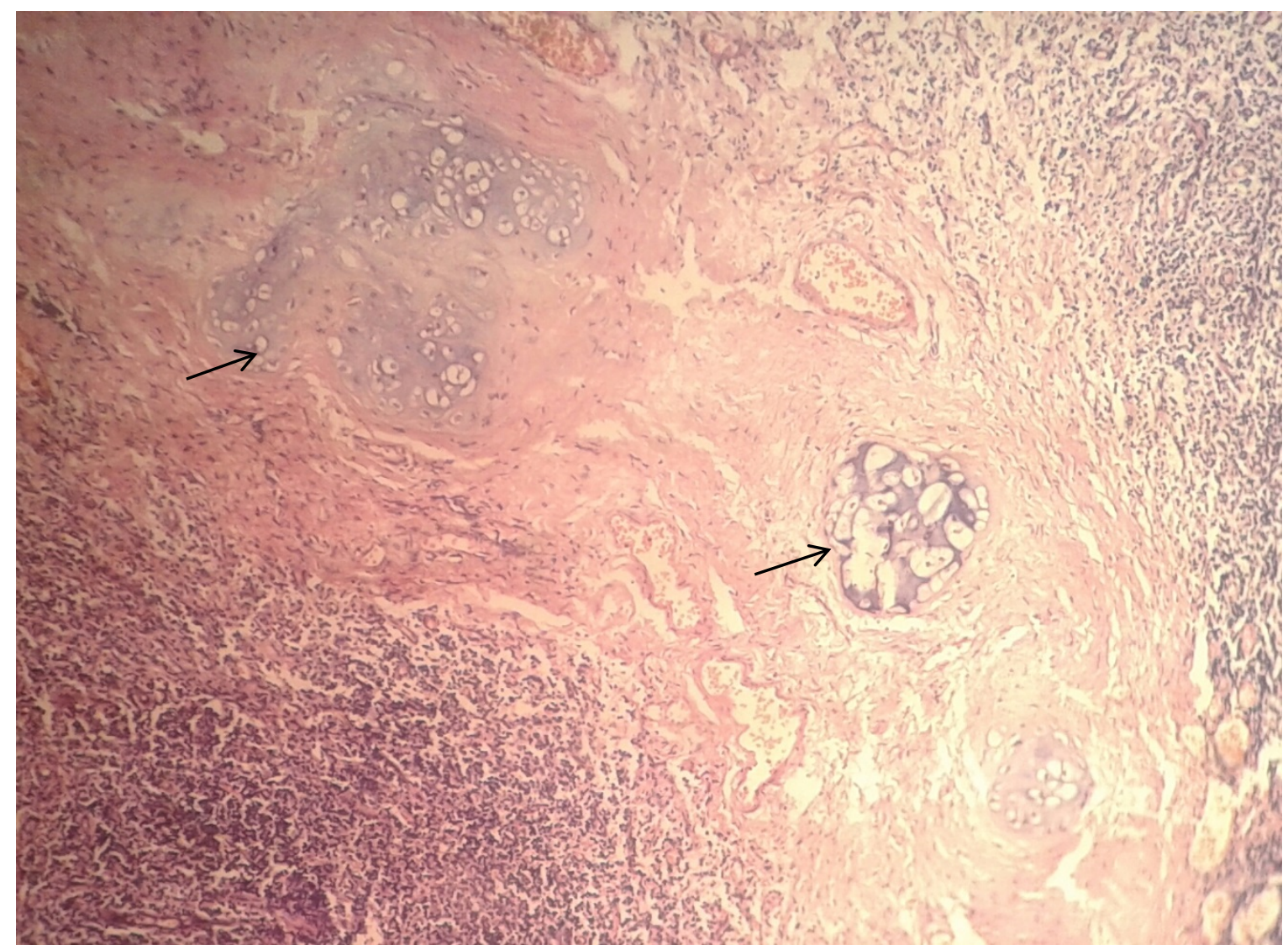

Fig 1. Microscopic picture lymphoid hyperplasia along with islands of mature hyaline cartilage.

\section{REFERENCES}

1. Bhargava D, Raman R, Khalfam Al Abri R,Bushnurmath B. Heterotopia of the tonsil. J Larangol Otol 1996; 10(6): 611-12.

2. Chou L S, Hansen L S, Daniel T E. Choristomas of the oral cavity: A Review. Oral Surg Oral med Oral Pathol 1991; 72(5): 584-593.

3. Lee FP. Cartilaginous choristoma of the bony external auditory canal: A study of 36 cases. Otolaryngol Head and Neck surgery 2005;133:786-90.

4. Wise JB, Seghal K Guttenberg M, Shah UK. Ectopic salivary tissue of the tonsil: a case report. Int J pediatrotorhinology 2005; 69:56771.

5. Bernig T, Meigel S, Mukodzi S, Bech J F, Wiersbitzhy $\mathrm{H}$, Von Suchodoletz H, Warzok R. Ectopiccervical thymus in a year old boy: A Case report. Pediatr Hematol Oncol 2000; 7 (8): 713-17.

6. Warcrenier A, Fayoux P, Augusto D. Gastric heterotopia in the nasopharynx. Int J Pediatr Otorhinolaryngol 2002; 64(1): 65-7.

7. Haemel A, Gnepp D R, Carlsten J et al.Heterotopic salivary gland tissue in the neck. J Am Acad Dermatol 2008; 58(2): 251-56.
8. Kapoor N, Bhalla J, Bharadwaj V K, Kotgirwar BK. Cartilaginous Choristoma of the palatine tonsil ACase Report. Indian J Pathol Microbiol 2003; 46(4):54-55.

9. Lindholm S T, Hackman R, Lindholm RV.Hisodynamics of experimental heterotopic osteogenesis by transitional epithelium. Acta Chiruagica Scandinavia 1973;139: 617-23.

10. Logan Turner Diseases of Tonsil (Chapter 16), edited by J F Birrell and assisted by G D McDowell; 5thedition, Jaypee publications New Delhi 2006. 